\title{
Effect of Sludge Biochars Obtained at Different Pyrolysis Temperatures on the Adsorption of Cd(II)by Loess in Northwestern China
}

\author{
Liang Dai, Jun Ren*, Ling Tao, Hua Li, JianXiu Hao \\ School of Environmental and Municipal Engineering, Lanzhou Jiaotong University, \\ Lanzhou, Gansu 730070, China
}

Received: 14 February 2017

Accepted: 16 March 2017

\begin{abstract}
The effect of sludge biochars obtained at different temperatures on the adsorption of $\mathrm{Cd}(\mathrm{II})$ by loess in northwestern China was investigated using the batch equilibrium method. The results showed that the pseudo second-order kinetic model can describe the kinetics of $\mathrm{Cd}(\mathrm{II})$ adsorption on the sludge biocharamended loess very well. The adsorption of $\mathrm{Cd}(\mathrm{II})$ by loess reached equilibrium in $6 \mathrm{~h}$. However, with the addition of biochar, the adsorption time of the Cd(II) by loess decreased. In addition, the adsorption equilibrium time decreased significantly with increasing pyrolysis temperatures. When the $\mathrm{pH}$ increased from 2 to 7, the adsorption capacity of biochar-amended loess increased, while the adsorption capacity was in equilibrium or even slightly decreased in the $\mathrm{pH}$ range from 7 to 8 . The Langmuir model can describe the adsorption isothermal behaviours of $\mathrm{Cd}(\mathrm{II})$ by biochar-amended loess. The adsorption capacity of biochar-amended loess samples for $\mathrm{Cd}(\mathrm{II})$ at $25^{\circ} \mathrm{C}$ follows the order of LSB700 $(28.74 \mathrm{mg} / \mathrm{g})>\mathrm{LSB} 500$ $(22.42 \mathrm{mg} / \mathrm{g})>\mathrm{LSB} 300(17.67 \mathrm{mg} / \mathrm{g})$. The addition of sludge biochars can significantly improve the saturation adsorption capacity of loess for $\mathrm{Cd}(\mathrm{II})$. Therefore, the addition of sludge biochars can effectively improve the adsorption-immobilization capability of loess for $\mathrm{Cd}(\mathrm{II})$.
\end{abstract}

Keywords: loess, pyrolysis, sludge biochar, adsorption, $\mathrm{Cd}(\mathrm{II})$

\section{Introduction}

In recent years, with economic development and the acceleration of urbanization and industrialization, heavy metal-contamination of soil has become increasingly severe. In particular, the accumulation, migration, and concentration of heavy metals in water and soil seriously threaten the environment and human health. Due to its solubility, mobility, and bioaccumulation, $\mathrm{Cd}$ is one of

*e-mail: renjun56563@126.com the most toxic heavy metals and it has received attention worldwide [1-2]. Cd-contaminated arable lands in China include 11 provinces and 25 regions [3], and these lands pose a serious threat to agricultural production and human health.

Biochar is a carbon-rich material made from biomass via pyrolysis in the presence of limited oxygen or the absence of oxygen. The raw materials include forest or agriculture residues, faeces, and sewage sludge. Biochar has shown excellent application potential in carbon sequestration [4], contaminated soil treatment [5-7], degraded soil restoration [8], soil nutrient retention, 
and increasing crop yield [9]. Because biochar has a low production cost and strong adsorption for organic pollutants (e.g., polycyclic aromatic hydrocarbons (PAHs) as well as antibiotics) and heavy metals (e.g., $\mathrm{Pb}, \mathrm{Cu}, \mathrm{Zn}$, and Cd) [10-12], it has the potential to be applied as an adsorbent for environmental protection on a large scale.

With urbanization progress and increasing public awareness of environmental protection in China, sludge output has increased rapidly. The output of wet sludge reached 22.67 million tons by the end of 2011 and is projected to reach 60 million tons by 2020 [13]; treatment of the toxic substance-containing sludge has become an important research topic in environmental disciplines. Sludge pyrolysis can eliminate smells and pathogenic bacteria, stabilize heavy metals, and recycle a certain amount of energy. Therefore, it is a very promising means for the treatment of sludge [14-15]. Due to the rich surface functional groups and its advanced porous structure, sludge biochar is a very promising cheap adsorbent. Research has shown that biochar derived from sludge exhibits a much higher adsorption capacity for $\mathrm{Cd}(\mathrm{II})$ than does commercially activated carbon. The main mechanism of the adsorption process of sludge biochar for $\mathrm{Cd}(\mathrm{II})$ involves: 1) surface precipitation by forming insoluble cadmium compounds in alkaline condition and 2) ion exchange for $\mathrm{Cd}(\mathrm{II})$ with exchangeable cations in the biochar matrix (e.g., $\mathrm{Ca}(\mathrm{II})$ and $\mathrm{Mg}$ (II)) [16]. The pyrolysis temperature can significantly affect the oxygen functional groups, mineral constituents, and aromatic structures in biochar, which may affect the adsorption capacity of Cd(II) [17].

Loess is one of the most widely distributed soils in China, and it is mostly distributed in the arid and semiarid seasonal soil-freezing cold and arid regions. Cold and arid regions are regions with fragile environments characterized by a loose soil structure, large porosity, strong permeability, poor aggregation capability, and low organic contents; in addition, the soil quality and its stability can be easily influenced by environmental and human activities. To date, the existing heavy metal soil restoration studies have mostly focused on acidic soils. The restoration of alkaline soils via the immobilization of heavy metals using sludge biochar has rarely been reported. Loess is the typical regional soil in northwestern China; however, the adsorption mechanism of $\mathrm{Cd}(\mathrm{II})$ onto loess and the interaction between loess and sludge biochar are not fully understood and thus need to be investigated. Therefore, biochar was prepared via pyrolysis at different temperatures using urban sludge as the raw material. The effects of the pyrolysis temperature on the physical and chemical properties of the biochar were investigated. The effects of adsorption time, initial $\mathrm{Cd}$ (II) concentration, and $\mathrm{pH}$ on the adsorption of Cd(II) by loess and sludge biocharamended loess were also investigated. The adsorption mechanism of $\mathrm{Cd}(\mathrm{II})$ by loess and sludge biocharamended loess was discussed to provide a reference and guidance to the adsorption-immobilization remediation of heavy metal-contaminated loess by amending it with sludge biochar.

\section{Materials and Methods}

\section{Preparation and Characterization of Sludge Biochar}

Sludge samples $(100 \mathrm{~kg}, 80.6 \%$ water content) were taken from the second sedimentation tank of the Anningqilihe wastewater treatment plant in Lanzhou, Gansu Province. The physical and chemical properties of the sludge are listed in Table 1. The wet sludge was air-dried for five days under natural conditions, and the dry sludge ( $5 \%$ water content) was ground into particles $\leq 5 \mathrm{~mm}$. The sludge was dried to a constant weight at $105^{\circ} \mathrm{C}$. A total of $10 \mathrm{~g}$ of dry sludge was placed in a porcelain combustion boat covered with a ceramic cover plate to avoid the loss of materials through ventilation. The porcelain combustion boat was placed in a horizontal tube furnace (SK-GO6123K, Zhonghuan Experimental Furnace Company, China); the tube had a diameter of $8 \mathrm{~cm}$ and a length of $100 \mathrm{~cm}$. First, the furnace was filled with nitrogen for $20 \mathrm{~min}$ at a flow rate of $1 \mathrm{~L} / \mathrm{min}$. Then the temperature was raised to the set temperature $\left(300,500\right.$, and $\left.700^{\circ} \mathrm{C}\right)$ at a heating rate of $6.5^{\circ} \mathrm{C} / \mathrm{min}$. The sludge was pyrolyzed for $1 \mathrm{~h}$ at the three set temperatures and then cooled to room temperature. The nitrogen flow rate was $0.5 \mathrm{~L} / \mathrm{min}$ during pyrolysis, and the nitrogen flow was maintained during the cooling process. After cooling, the sample was ground, sifted through $2 \mathrm{~mm}$ sieves, and stored for use. The sludge biochars prepared at 300,500 , and $700^{\circ} \mathrm{C}$ were labelled as SB300, SB500, and SB700, respectively.

A specific surface area analyser (Micromeritics ASAP 2020, Mike Instruments, USA) was used to determine the specific surface area, pore volume and pore size of the sludge biochars by the $\mathrm{N}_{2}$ adsorption-desorption isotherm

Table 1. Physico-chemical properties of sewage sludge and loess.

\begin{tabular}{|c|c|c|}
\hline Parameters & Sewage sludge & Loess \\
\hline $\mathrm{pH}($ soil $/$ water $=1: 5)$ & $6.23(0.20)^{*}$ & $8.27(0.26)$ \\
\hline $\begin{array}{c}\mathrm{EC}(\mathrm{dS} / \mathrm{m}) \\
(\text { soil } / \text { water }=1: 5)\end{array}$ & $3.02(0.12)$ & $0.21(0.01)$ \\
\hline Organic carbon $(\mathrm{g} / \mathrm{kg})$ & $472.47(2.86)$ & $8.47(0.61)$ \\
\hline Moisture content $(\%)$ & $80.6(0.36)$ & $10.05(0.96)$ \\
\hline Total $\mathrm{N}(\mathrm{g} / \mathrm{kg})$ & $39.49(1.66)$ & $0.71(0.06)$ \\
\hline Total $\mathrm{P}(\mathrm{g} / \mathrm{kg})$ & $21.31(1.13)$ & $0.82(0.12)$ \\
\hline Total $\mathrm{K}(\mathrm{g} / \mathrm{kg})$ & $9.57(0.28)$ & $12.38(1.11)$ \\
\hline Total $\mathrm{Cd}(\mathrm{mg} / \mathrm{kg})$ & $1.92(0.12)$ & $0.29(0.02)$ \\
\hline Total $\mathrm{Cr}(\mathrm{mg} / \mathrm{kg})$ & $115.69(8.65)$ & $32.05(2.33)$ \\
\hline Total $\mathrm{Zn}(\mathrm{mg} / \mathrm{kg})$ & $367.59(28.11)$ & $52.18(14.68)$ \\
\hline Total $\mathrm{Cu}(\mathrm{mg} / \mathrm{kg})$ & $78.29(3.86)$ & $35.26(2.65)$ \\
\hline Total $\mathrm{Ni}(\mathrm{mg} / \mathrm{kg})$ & $56.03(3.17)$ & $30.39(2.34)$ \\
\hline
\end{tabular}

*Values in parentheses are standard deviation of means of triplicate. 
at $77 \mathrm{~K}$. The Brunauer-Emmett-Teller (BET) model, the Barrett-Joyner-Halenda (BJH) model, and the t-plot method [18] were used to analyze the pore size distribution and specific surface area of biochar. An elemental analyser (Vario EL III,Elementar, Germany) was used to measure the elemental compositions of the samples. The biochar solution was prepared by mixing $1 \mathrm{~g}$ of biochar and $20 \mathrm{ml}$ of ultrapure water. After sufficient stirring for $1.5 \mathrm{~h}$, the solution was stationary for $1 \mathrm{~h}$ before the $\mathrm{pH}$ was measured using a $\mathrm{pH}$ meter.

\section{Test Soil}

Fifty kilograms of natural loess was obtained from the surface soil $(0-25 \mathrm{~cm})$ of vegetable fields in the suburbs of Lanzhou, Gangsu Province; the soil is a calcisol. After removing the stones, withered branches, and leaves, the soil was air-dried, ground, sifted through $0.15 \mathrm{~mm}$ sieves, and then stored in bags. The general properties of the soil were determined as follows: the $\mathrm{pH}$ and EC were measured on soil extract at a soil/double-distilled water ratio of 1:5 (w/v) using a pH meter and conductivity meter, respectively. Organic matter was calculated from the content of organic carbon using the conversion factor of 1.724. Total organic carbon was analyzed by dry oxidation of organic carbon to $\mathrm{CO}_{2}$ using an elemental analyzer (Vario EL III, Germany). Total nitrogen was determined by a modified Kjeldahl method using titanium dioxide as catalyst [19]. The total contents of heavy metals $(\mathrm{Cd}, \mathrm{Cr}$, $\mathrm{Zn}, \mathrm{Cu}$, and $\mathrm{Ni}$ ) as well as nutrients ( $\mathrm{K}$ and $\mathrm{P})$ in the soil and sludge were determined after aqua regia combustion using atomic absorption spectrometry (220FS, Varian, USA). The basic physical and chemical properties of the soil are listed in Table 1.

\section{Adsorption Experiment}

Effect of initial $\mathrm{pH}$ on adsorption capacity: The loess or sludge biochar-amended loess (SB300, SB500, and SB700 were mixed with clean loess at a mass ratio of 1:10 and labelled as LSB300, LSB500, and LSB700, respectively), weighed $(0.1000 \mathrm{~g})$, and added to $50 \mathrm{ml}$ centrifuge tubes. Then 40 mlof a $\mathrm{Cd}(\mathrm{II})$ solution with an initial concentration of $80 \mathrm{~mol} / \mathrm{L}$ was added to the tube. The solution contained $0.01 \mathrm{~mol} / \mathrm{L} \mathrm{NaNO}_{3}$ as the supporting electrolyte. Solution $\mathrm{pH}$ was adjusted to 2, 3, $4,5,6,7$, and 8 . The solution was shaken in a water bath at $140 \mathrm{r} / \mathrm{min}$ and $25^{\circ} \mathrm{C}$ for $24 \mathrm{~h}$. After standing for $2 \mathrm{~h}$, the solution was centrifuged at 4,000 r/min and filtered through a $0.45 \mu \mathrm{m}$ filter; the $\mathrm{Cd}(\mathrm{II})$ concentration in the supernatant was measured to calculate the equilibrium adsorption of $\mathrm{Cd}(\mathrm{II})$ in the solution by the adsorbents with different $\mathrm{pH}$ values.

Adsorption kinetics experiment: the loess or biocharamended loess was weighed $(0.1000 \mathrm{~g})$ and added to $50 \mathrm{ml}$ centrifuge tubes, and then $40 \mathrm{ml}$ of a Cd(II) solution with a concentration of $80 \mathrm{mg} / \mathrm{Lwas}$ added to the tube. The $\mathrm{pH}$ was adjusted to 5.0 using a dilute $\mathrm{HNO}_{3}$ or $\mathrm{NaOH}$ solution, and $0.01 \mathrm{~mol} / \mathrm{L} \mathrm{NaNO}_{3}$ was used as the background electrolyte. The centrifuge tube was shaken at $140 \mathrm{r} / \mathrm{min}$ and $25^{\circ} \mathrm{C}$. The supernatant was sampled at $0.2-10 \mathrm{~h}$ and filtered through $0.45 \mu \mathrm{m}$ filters to measure the residual $\mathrm{Cd}(\mathrm{II})$ concentration as well as study the adsorption kinetics characteristics.

Isothermal adsorption experiment: The loess or biochar-amended loess was weighed $(0.1000 \mathrm{~g})$ and added to $50 \mathrm{ml}$ centrifuge tubes; then 40 mlof a Cd(II) solution with an initial concentration of 20,40,60, 80, 100, 120, 160,200 , and $300 \mathrm{mg} / \mathrm{L}$ was added to the tube. $\mathrm{NaNO}_{3}$ $(0.01 \mathrm{~mol} / \mathrm{L})$ was used as the supporting electrolyte for all of the solutions, and the initial solution $\mathrm{pH}$ was adjusted to 5.0. The solution was shaken in a water bath at $140 \mathrm{r} / \mathrm{min}$ and $25^{\circ} \mathrm{C}$ for $24 \mathrm{~h}$. After standing for $2 \mathrm{~h}$, the solution was centrifuged at $4,000 \mathrm{r} / \mathrm{min}$ for $20 \mathrm{~min}$ and filtered through a $0.45 \mu \mathrm{m}$ filter; the $\mathrm{Cd}$ (II) concentration in the supernatant was measured.

\section{Data Analysis and Calculation Method}

Equilibrium adsorption capacity: After the adsorption equilibrium was achieved, the equilibrium adsorption amount $\left(q_{e}\right)$ was calculated by the following equation:

$$
q_{e}=V\left(C_{0}-C_{e}\right) / m
$$

... where $q_{e}$ is the adsorption capacity at equilibrium ( $\mathrm{mg} / \mathrm{g}$ ); $C_{0}$ and $C_{e}$ are the initial and equilibrium concentrations of $\mathrm{Cd}(\mathrm{II})$ ions in solution, respectively $(\mathrm{mg} / \mathrm{L}) ; V$ is the volume of solution $(L)$; and $m$ is the mass of the adsorbent (g).

Adsorption kinetics: The adsorption kinetics study the rate of adsorption. The common pseudo first-order kinetics model, pseudo second-order kinetics model, and intraparticle diffusion model were used in this paper to fit the experimental data. The model equations are as follows: - The pseudo first-order kinetic model is expressed as:

$$
\ln \left(q_{e}-q_{t}\right)=\ln q_{e}-k_{1} t
$$

- The pseudo second-order kinetic model is expressed as:

$$
\frac{t}{q_{t}}=\frac{1}{k_{2} q_{e}^{2}}+\frac{t}{q_{e}}
$$

- The intraparticle diffusion model can be calculated using the following equation:

$$
q_{t}=k_{t} t^{0.5}+C
$$

...where $q_{e}$ is the adsorption capacity at equilibrium $(\mathrm{mg} / \mathrm{g}), t$ is the adsorption time ( $\mathrm{min}), q_{t}$ is the amount of metal ions adsorbed at time $\mathrm{t}(\mathrm{mg} / \mathrm{g}), k_{1}$ is the pseudo first-order rate constant, $k_{2}$ is the rate constant of the pseudo second-order adsorption, and $C$ is the intraparticle diffusion rate constant. 
Adsorption isotherm: the Langmuir and Freundlich models were used to fit the experimental data from the adsorption equilibrium at $25^{\circ} \mathrm{C}$ for a concentration in the range of $20-300 \mathrm{mg} / \mathrm{L}$.

The Langmuir model can be expressed as follows:

$$
\frac{C_{e}}{q_{e}}=\frac{1}{q_{m} K_{L}}+\frac{C_{e}}{q_{m}}
$$

The Freundlich model is:

$$
\ln q_{e}=\ln K_{F}+\frac{1}{n} \ln C_{e}
$$

...where $C_{e}$ is the equilibrium concentration of the metal ion $(\mathrm{mg} / \mathrm{L}), q_{e}$ is the adsorption capacity at equilibrium $(\mathrm{mg} / \mathrm{g})$, and $q_{m}$ is the saturated adsorption capacity. $K_{L}$ and $K_{F}$ are the Langmuir and Freundlich adsorption constants $(\mathrm{L} / \mathrm{g})$, respectively, and $n$ is a temperature-dependent constant.

The Cd(II) concentration in the solution was measured using an atomic absorption spectrophotometer (220FS, Varian, USA). All samples had three repetitions, and all measurements were repeated three times. The average of the measurements was used as the result.

\section{Results and Discussion}

\section{Characterization of the Physical and Chemical Properties of Sludge Biochars}

The physical and chemical properties of biochars derived from the pyrolysis of sludge at different temperatures are listed in Table 2. The comparison of the relevant data in the table shows that the yield of the biochars decreased with increasing pyrolysis temperatures, which is because the volatile components in the sludge biomass are gradually emitted from the raw material as the pyrolysis temperature increases, resulting in fewer residual components.

The $\mathrm{pH}$ of the sludge biochars increased with increasing pyrolysis temperatures. The $\mathrm{pH}$ of SB700 reached 9.97, and the sample transitioned from an acid sludge to an alkaline biochar. Because the organic matter content in the sludge reached $49.7 \%$, the organic acids produced from the decomposition of organic matter led to a weak acidity for the raw sludge. In the pyrolysis of the sludge samples, the organic matter continued to decompose and the ash content gradually accumulated as the temperature increased. Therefore, the biochar exhibited alkaline characteristics.

The measured elemental compositions can be used to effectively analyse the properties and structures of biochars. As the pyrolysis temperature increased, the $\mathrm{C}$, $\mathrm{H}, \mathrm{N}$, and $\mathrm{O}$ contents in the sludge biochar continually decreased. The $\mathrm{H}$ content decreased most rapidly, from $4.78 \%$ in the raw sludge to $0.52 \%$ in SB700. Research [20] has shown that the elemental ratios of $\mathrm{O} / \mathrm{C}, \mathrm{H} / \mathrm{C}$, and $(\mathrm{O}+\mathrm{N}) / \mathrm{C}$ can be used to characterize hydrophilicity, aromaticity, and polarity, respectively. As the pyrolysis temperature increased, the $\mathrm{O} / \mathrm{C}$ and $(\mathrm{O}+\mathrm{N}) / \mathrm{C}$ values of the biochars gradually decreased, which indicated that the hydrophilicity and polarity of the biochars gradually deceased with increasing pyrolysis temperatures and that the amount of oxygen-containing functional groups in biochars gradually decreased. The $\mathrm{H} / \mathrm{C}$ ratio also gradually decreased with increasing pyrolysis temperatures, which showed that the aromaticity and stability of the pyrolysis products gradually improved. The degree of aromaticity in the pyrolysis products increased while the polarity decreased, and these results are consistent with the results by Yoshida et al. [21]. Hence, the properties of sludge biochar are more stable with increasing pyrolysis temperatures.

The specific surface area and structural parameters of the pores for the sludge biochars are listed in Table 3 . The water on the surfaces and bodies as well as highly volatile and easily oxidized components of the sludge are lost in pyrolysis. In addition, the degree of pyrolysis of the sludge increased with increasing temperatures, which resulted in the gradual growth of the porous structure in the sludge. The increase in the quantity of micropores and the volume of the pores led to increased specific surface area and porosity. The BET average pore diameters of the biochars exhibited the order of LSB500 > LSB300 > LSB700. This is likely because when the pyrolysis temperature increased from $300^{\circ} \mathrm{C}$ to $500^{\circ} \mathrm{C}$, mesopores and macropores gradually grew on the biochars, which resulted in an increase in the average pore diameter. However, when the pyrolysis temperature increased from $500^{\circ} \mathrm{C}$ to $700^{\circ} \mathrm{C}$, the higher temperature caused a partial collapse of the macropores and increased the proportion of micropores, which led to a decrease in the average pore diameter. The results indicated that an excessively high pyrolysis temperature is not beneficial for the growth of the porous structure. The BET-specific surface of the biochars derived from sludge are smaller than those that the biochars derived

\begin{tabular}{|c|c|c|c|c|c|c|c|c|c|c|c|}
\hline \multirow{2}{*}{ Treatment } & \multirow{2}{*}{ Yields } & \multirow{2}{*}{$\mathrm{pH}$} & \multicolumn{5}{|c|}{ Element content $(\%)$} & \multicolumn{4}{|c|}{ Elemental ratio } \\
\hline & & & $\mathrm{C}$ & $\mathrm{H}$ & $\mathrm{N}$ & S & $\mathrm{O}$ & $\mathrm{O} / \mathrm{C}$ & $\mathrm{H} / \mathrm{C}$ & $\mathrm{C} / \mathrm{N}$ & $(\mathrm{O}+\mathrm{N}) / \mathrm{C}$ \\
\hline SB300 & $84.6 \%$ & 7.09 & 30.90 & 3.87 & 5.32 & 1.11 & 36.21 & 1.17 & 0.13 & 5.81 & 1.34 \\
\hline SB500 & $50.2 \%$ & 9.17 & 27.06 & 1.00 & 3.42 & 1.25 & 30.16 & 1.11 & 0.04 & 7.91 & 1.24 \\
\hline SB700 & $48.9 \%$ & 9.97 & 21.10 & 0.52 & 2.11 & 1.05 & 23.15 & 1.10 & 0.02 & 10.00 & 1.20 \\
\hline
\end{tabular}

Table 2. Yields, $\mathrm{pH}$ value, and major elemental compositions of sludge biochar under different temperatures. 
Table 3. Specific surface areas and porosity of sludge biochar.

\begin{tabular}{|c|c|c|c|c|c|c|c|}
\hline Treatment & $\begin{array}{c}\text { BET } \\
\text { surface area } \\
\left(\mathrm{m}^{2} / \mathrm{g}\right)\end{array}$ & $\begin{array}{c}\text { BJH adsorption } \\
\text { accumulation } \\
\text { surface area } \\
\left(\mathrm{m}^{2} / \mathrm{g}\right)\end{array}$ & $\begin{array}{c}\text { T-pLot } \\
\text { micropore } \\
\text { area }\left(\mathrm{m}^{2} / \mathrm{g}\right)\end{array}$ & $\begin{array}{c}\text { Single point } \\
\text { adsorption total } \\
\text { pore volume of } \\
\text { pores }\left(\mathrm{cm}^{3} / \mathrm{g}\right)\end{array}$ & $\begin{array}{c}\text { BJH Adsorption } \\
\text { cumulative } \\
\text { volume of pores } \\
\left(\mathrm{cm}^{3} / \mathrm{g}\right)\end{array}$ & $\begin{array}{c}\text { T-pLotmicropore } \\
\text { volume } \\
\left(\mathrm{cm}^{3} / \mathrm{g}\right)\end{array}$ & $\begin{array}{c}\text { Adsorption } \\
\text { average pore } \\
\text { width }(\mathrm{nm})\end{array}$ \\
\hline SB300 & 10.85 & 3.95 & 4.85 & $2.11 \times 10^{-2}$ & $6.45 \times 10^{-2}$ & $3.79 \times 10^{-2}$ & 7.690 \\
\hline SB500 & 16.55 & 6.05 & 16.55 & $9.05 \times 10^{-2}$ & $15.5 \times 10^{-2}$ & $3.83 \times 10^{-2}$ & 8.905 \\
\hline SB700 & 22.80 & 5.75 & 20.80 & $5.40 \times 10^{-2}$ & $8.11 \times 10^{-2}$ & $5.25 \times 10^{-2}$ & 4.253 \\
\hline
\end{tabular}

from agricultural and forest residues, such as straws and livestock faeces [22]; this is likely because agricultural and forest residues contain high cellulose content, which can form micropores from pyrolysis.

\section{Effect of Solution pH on Adsorption Capacity}

The $\mathrm{pH}$ of a solution affects the surface charge of the adsorbents, ion exchange between the adsorbent and adsorbate, and speciation of metals in solution. Therefore, it is an important factor that impacts the adsorption of metals [23-24]. The variation in the adsorption capacity of $\mathrm{Cd}(\mathrm{II})$ by loess and biochar-amended loess with a changing initial solution $\mathrm{pH}$ is shown in Fig. 1. When the $\mathrm{pH}$ ranged from 2 to 5 , the adsorption capacity of $\mathrm{Cd}(\mathrm{II})$ by the adsorbents increased rapidly with increasing $\mathrm{pH}$. The adsorption capacities of Loess, LSB300, LSB500, and LSB700 were 6.98, 11.10, 13.56, and $16.96 \mathrm{mg} / \mathrm{g}$, respectively, when $\mathrm{pH}=5$. When the $\mathrm{pH}$ increased from 5 to 7 , the adsorption capacities of the adsorbents for $\mathrm{Cd}(\mathrm{II})$ increased slightly, and the rate of the adsorption capacity increase slowed significantly. When the $\mathrm{pH}$ ranged from 7 to 8 , the adsorption capacity remained the same or slightly decreased. The differences between the maximum and minimum adsorption capacities for $\mathrm{Cd}(\mathrm{II})$ at different solution $\mathrm{pH}$ values for Loess, LSB300, LSB500, and LSB700 were 5.88, 11.76, 14.00, and 19.40, respectively, which indicates that the initial $\mathrm{pH}$ of the solution exerts a significant impact on the adsorption of

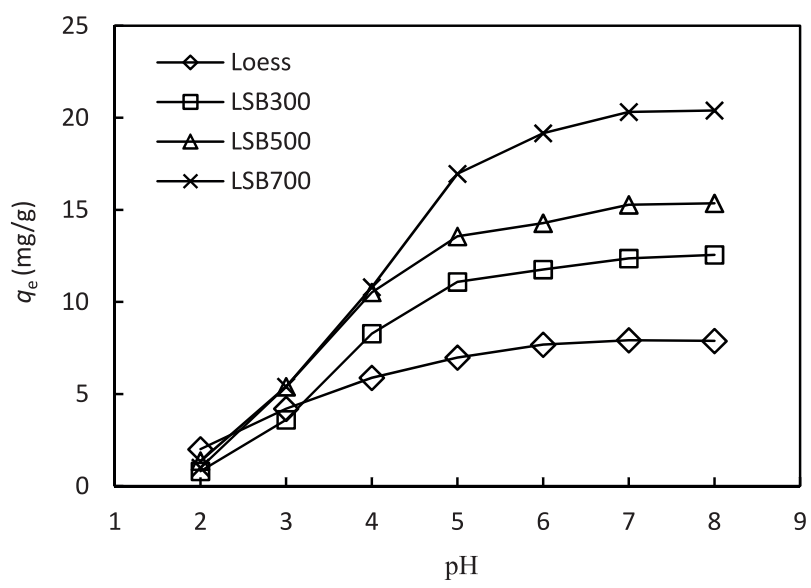

Fig. 1. Effect of solution $\mathrm{pH}$ on the adsorption of Cd(II) by loess and biochar-amended loess.
Cd(II) by loess. When the $\mathrm{pH}$ was low, the $\mathrm{H}^{+}$and $\mathrm{Cd}(\mathrm{II})$ in solution competitively adsorbed on the binding sites. However, when $\mathrm{pH}$ increased, the competitive advantage of $\mathrm{H}^{+}$weakened and more binding sites were released. As a result, the adsorption efficiency of Cd(II) was improved. When the $\mathrm{pH}$ reached 7 , the adsorption capacity reached a maximum. However, upon further increase in the $\mathrm{pH}$, certain adsorbents exhibited a slight decrease in their adsorption capacities for $\mathrm{Cd}(\mathrm{II})$ because $\mathrm{Cd}(\mathrm{II})$ formed precipitates with $\mathrm{OH}^{-}$in the solution.

\section{Adsorption Kinetics}

Fig. 2 shows the kinetic curves for $\mathrm{Cd}(\mathrm{II})$ adsorption by loess and biochar-amended loess at $25^{\circ} \mathrm{C}$. The figure shows that the addition of sludge biochars to loess can effectively improve the saturation adsorption capacity of loess for Cd(II). At the same time, the adsorption of Cd(II) by loess without biochars reached an equilibrium at approximately $6 \mathrm{~h}$, and the adsorption time was shortened if sludge biochars were added. The decrease in the adsorption equilibrium time was more pronounced with increasing pyrolysis temperatures. The $\mathrm{Cd}(\mathrm{II})$ adsorption equilibrium time on LBS700 was $3 \mathrm{~h}$; the saturation adsorption capacity of $\mathrm{Cd}(\mathrm{II})$ increased from 5.16 to $16.72 \mathrm{mg} / \mathrm{g}$, i.e., $177.74 \%$. Fig. 2 clearly shows that the increases of the saturation adsorption capacity of loess amended with biochars obtained at different pyrolysis temperatures follows the order of LBS700 $>$ LBS500 $>$ LBS300. The capacity exhibited a

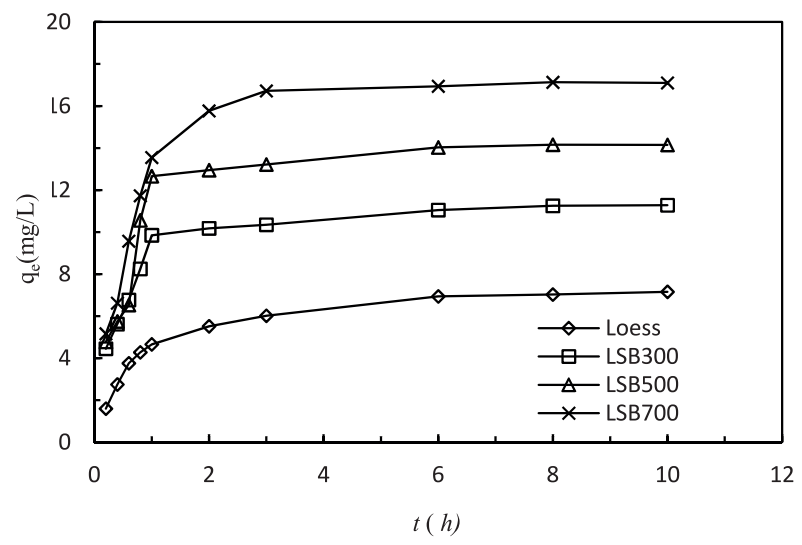

Fig. 2. Kinetics curves for the adsorption of Cd(II) on loess soil in the presence of sludge biochar. 
rapid and then slow adsorption trend. From 0 to $1 \mathrm{~h}$, as the adsorption time was prolonged, the adsorption capacities of the four adsorbents for Cd(II) rapidly increased. From 1 to $6 \mathrm{~h}$, the rate of increase the adsorption capacity gradually slowed, and the adsorption capacity reached equilibrium at approximately $6 \mathrm{~h}$. The loess and biochar-amended loess exhibited two stages of rapid and slow reaction. This is likely because there are many binding sites on the surface of the biochars and the molecular concentration difference is large between the liquid phase and the surface of the biochars in the initial stage of the adsorption. As a result, $\mathrm{Cd}$ (II) can easily diffuse and adsorb onto the outer surface of the adsorbents. As the adsorption proceeds, the binding sites on the outer surface are gradually saturated, and the adsorption enters a slow reaction stage. At this time, the reaction rate is mainly controlled by the diffusion rate of heavy metal ions inside the micropores of the adsorbents [25-26]. The adsorbates gradually diffuse from the macropores deep into the micropores. The mass transfer rate of heavy metals inside the inner pores slows, and the adsorption rate slightly increases until equilibrium is reached.

To study the adsorption mechanism of $\mathrm{Cd}(\mathrm{II})$ by loess and biochar-amended loess, the common pseudo first-order kinetic equation, pseudo second-order kinetic equation and intraparticle diffusion equation were used to linearly fit the adsorption process; the results are shown in Table 4, which shows that the pseudo first-order kinetic model and the pseudo second-order kinetic model give a better fit compared to the intraparticle diffusion equation. The correlation coefficient $\mathrm{R}^{2}$ values of the pseudo second-order kinetic equation for the four adsorbents were all greater than 0.99 , which is better than the $\mathrm{R}^{2}$ obtained from the fit of the pseudo first-order kinetic equation. In addition, the equilibrium adsorption capacity calculated using the pseudo second-order kinetic equation was very close to the experimental value, which indicated that the adsorption kinetics characteristics of $\mathrm{Cd}$ (II) onto the biochar-amended loess conform better to the pseudosecond order kinetic equation. These results suggest that the adsorption rate is mainly controlled via chemical adsorption; the adsorption process includes surface adsorption, intraparticle diffusion, and external fusion [27]. The rate constant $k_{2}$ of the pseudo second-order kinetic equation reflects the rate of the $\mathrm{Cd}(\mathrm{II})$ adsorption by biochars; the $k_{2}$ values of the three biochar-amended loess samples follows the order of LSB300>LSB500>LSB700. The likely reason for the small $k_{2}$ for the loess amended with biochars produced from high temperature pyrolysis is that the increase in the pyrolysis temperature decreases the acid functional groups on the surface of the biochars. In addition, inorganic elements such as $\mathrm{Ca}, \mathrm{Mg}$, and $\mathrm{P}$ in the biochars produced from high-temperature pyrolysis form insoluble phosphate and carbonate crystals, resulting in a slow release rate of phosphate [28] and carbonate ions, thus decreasing the reaction rate with $\mathrm{Cd}(\mathrm{II})$.

\section{Effect of Different Initial Concentrations on Adsorption Capacity}

The relationships between the adsorption capacities of $\mathrm{Cd}(\mathrm{II})$ by loess and biochar-amended loess and the initial concentration are found in Fig. 3, which shows that the adsorption capacities of $\mathrm{Cd}(\mathrm{II})$ for the four adsorbents increased with increasing initial concentrations, and the adsorption capacities of the three biochar-amended loess samples were higher than those of the loess without biochars for each initial concentration. When the initial concentration ranged from 20 to $120 \mathrm{mg} / \mathrm{L}$, the adsorption capacities of Cd(II) by loess and SB300 increased rapidly from 3.16 to $4.95 \mathrm{mg} / \mathrm{g}$ and from 8.72 to $13.63 \mathrm{mg} / \mathrm{g}$, respectively. The adsorption capacity almost reached equilibrium at $120 \mathrm{mg} / \mathrm{L}$, whereas for LSB500 and LSB700 the adsorption capacities increased rapidly when the initial concentration ranged from 20 to $200 \mathrm{mg} / \mathrm{L}$ and almost reached equilibrium at $200 \mathrm{mg} / \mathrm{L}$. Then, with further increases of the initial concentration, the adsorption capacity increased slowly and finally approached equilibrium. The higher the initial concentration, the greater the concentration gradient at the solid-liquid interface, which makes it easier to overcome the mass transfer resistance between the two phases, thus promoting the migration of $\mathrm{Cd}(\mathrm{II})$ from the solution to the surface of the solids [25]. As a result, the higher the initial concentration, the greater the corresponding adsorption capacity. Overall, the addition of biochar effectively improves the adsorption capacity of $\mathrm{Cd}(\mathrm{II})$ on loess, and the larger the initial concentration of $\mathrm{Cd}(\mathrm{II})$, the greater the increase of adsorption capacity. The different initial concentrations exert a significant impact on the adsorption of Cd(II) by loess.

Table 4. Regression parameters of the sorption kinetics of Cd(II) by loess and biochar-amended loesses.

\begin{tabular}{|c|c|c|c|c|c|c|c|c|c|c|c|}
\hline \multirow{2}{*}{ Adsorbent } & \multirow{2}{*}{$q_{e, e x p}$} & \multicolumn{3}{|c|}{$\begin{array}{c}\text { Pseudo first-order kinetic } \\
\text { model }\end{array}$} & \multicolumn{2}{|c|}{$\begin{array}{c}\text { Pseudo second-order kinetic } \\
\text { model }\end{array}$} & \multicolumn{4}{c|}{ Intraparticle diffusion model } \\
\cline { 3 - 13 } & & $q_{e, \text { cal }}$ & $k_{1}$ & $R^{2}$ & $q_{e, \text { al }}$ & $k_{2}$ & $R^{2}$ & $q_{e, \text { cal }}$ & $k_{t}$ & $C$ & $R^{2}$ \\
\hline Loess & 7.17 & 5.312 & 0.521 & 0.963 & 7.657 & 0.187 & 0.996 & 7.924 & 1.812 & 2.194 & 0.853 \\
\hline LSB300 & 11.29 & 6.442 & 0.624 & 0.980 & 11.737 & 0.216 & 0.999 & 12.34 & 2.219 & 5.323 & 0.790 \\
\hline LSB500 & 14.16 & 6.987 & 0.677 & 0.934 & 14.903 & 0.155 & 0.997 & 15.965 & 3.122 & 6.092 & 0.652 \\
\hline LSB700 & 17.14 & 8.232 & 0.664 & 0.898 & 18.051 & 0.126 & 0.998 & 19.449 & 3.941 & 6.986 & 0.705 \\
\hline
\end{tabular}

a: exp show experimental value, cal show calculated value 


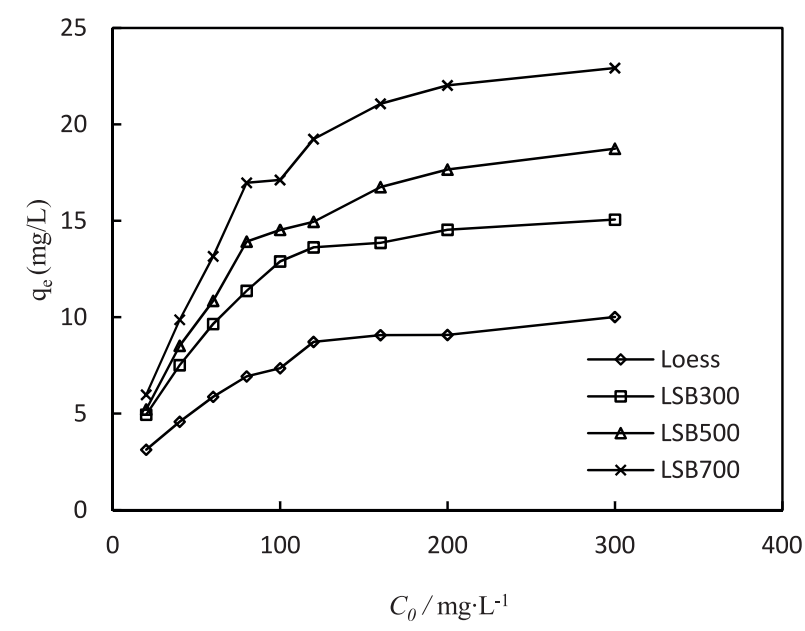

Fig. 3. Effect of different initial concentrations on adsorption of $\mathrm{Cd}(\mathrm{II})$ on loess affected by sludge biochar.

\section{Isothermal Adsorption Characteristics}

The adsorption isotherm is a curve describing the relationship between the amount of adsorbate on the surface of the adsorbent and that in the solution. The Langmuir and Freundlich models were used to fit the experimental data for $\mathrm{Cd}(\mathrm{II})$ adsorption. The parameters of the fitted model are shown in Table 5. The Langmuir adsorption equation assumes that a large number of active adsorption centres compose the solid surface. When these active adsorption centres are occupied, the adsorption capacity reaches saturation. In addition, the adsorbates form a monolayer on the surface of the adsorbents. However, the Freundlich isotherm equation describes multilayer adsorption [29]. The $\mathrm{K}_{\mathrm{F}}$ value in the Freundlich model can be used to characterize the adsorption capability of the adsorbents. The $\mathrm{K}_{\mathrm{F}}$ values of the three biochar-amended loess samples are greater than that of the loess without biochars. Among the biochar-amended loess samples, LSB700 has the largest $\mathrm{K}_{\mathrm{F}}$. This is likely because with the increase of the pyrolysis temperature the sludge biochars characterized a much larger surface area and content of ash. The large specific surface area can provide more binding sites and increase the potential adsorption capacity, which is also confirmed by the $\mathrm{q}_{\mathrm{m}}$ of LSB700. The adsorption capacity of Cd(II) by the biocharamended loess samples follows the order of LSB700 (28.74 $\mathrm{mg} / \mathrm{g})>\operatorname{LSB} 500(22.42 \mathrm{mg} / \mathrm{g})>\mathrm{LSB} 300 \quad(17.67$ $\mathrm{mg} / \mathrm{g}$ ), which agrees with the order of the BET-specific area and aromaticity of the three biochars and is opposite to that of the polarity. The adsorption capacities of the biochar-added loess samples are significantly greater than the loess without biochar. Among those, the adsorption capacity of LSB700 increased by $155.7 \%$ compared to the loess without biochars. The fitting results show that both models can fit the adsorption data well; the linear correlation coefficient $\mathrm{R}^{2}$ exceeds 0.92 for both. However, the $\mathrm{R}^{2}$ of the Langmuir model is higher. In addition, the maximum adsorption capacity, $\mathrm{q}_{\mathrm{m}}$ (calculated from the Langmuir fitting equation), is closer to the experimental data. Thus, the Langmuir model can better describe the adsorption isothermal behaviours of $\mathrm{Cd}(\mathrm{II})$ by the four adsorbents, which indicates that the adsorption of $\mathrm{Cd}$ (II) by the adsorbents is mainly monolayer adsorption.

\section{Conclusions}

1. As the initial $\mathrm{pH}$ of the solution increases, the adsorption capacity of $\mathrm{Cd}$ (II) by loess and biochar-amended loess first shows a rapid increase and then a slow increase, reaching a maximum at a $\mathrm{pH}$ of 7.0. The $\mathrm{Cd}(\mathrm{II})$ adsorption capacities of the four adsorbents can be arranged in the following order: LSB700> LSB500 $>$ LSB300 $>$ Loess.

2. The adsorption of $\mathrm{Cd}(\mathrm{II})$ by loess without biochar reached an equilibrium at approximately $6 \mathrm{~h}$, and the adsorption time was shortened if sludge biochar was added. The decreased equilibrium adsorption time was more pronounced with increasing sludge pyrolysis temperatures; furthermore, the saturation adsorption capacity of $\mathrm{Cd}(\mathrm{II})$ by sludge biochar-amended loess also increased significantly. The adsorption of $\mathrm{Cd}(\mathrm{II})$ by loess and biochar-amended loess exhibited a rapid increase from $0-1 \mathrm{~h}$ and a slow increase from 1-6 h; the adsorption capacity gradually reached equilibrium at approximately $6 \mathrm{~h}$. The pseudo second-order kinetic model can describe the kinetics of $\mathrm{Cd}(\mathrm{II})$ adsorption on the sludge biochar-amended loess very well; the adsorption process includes surface adsorption, intraparticle diffusion, and external fusion.

3. The adsorption capacities of Cd(II) by loess and biochar-amended loess increase with an increasing initial solution concentration. The addition of biochar effectively improves the adsorption capacity of Cd (II) on

Table 5. Parameters of isotherm fitting for Cd(II) sorption on loess affected by sludge biochar.

\begin{tabular}{|c|c|c|c|c|c|c|}
\hline \multirow{2}{*}{ Adsorbent } & \multicolumn{3}{|c|}{ Langmuir isotherm model } & \multicolumn{3}{c|}{ Freundlich isotherm model } \\
\cline { 2 - 7 } & $\mathrm{R}^{2}$ & $\mathrm{~K}_{\mathrm{L}}(\mathrm{L} / \mathrm{g})$ & $q_{m}(\mathrm{mg} / \mathrm{g})$ & $\mathrm{R}^{2}$ & $\mathrm{~K}_{\mathrm{F}}(\mathrm{L} / \mathrm{g})$ & $\mathrm{n}$ \\
\hline Loess & 0.987 & 0.0228 & 11.24 & 0.961 & 1.056 & 0.418 \\
\hline LSB300 & 0.992 & 0.0145 & 17.67 & 0.929 & 1.893 & 0.436 \\
\hline LSB500 & 0.996 & 0.0114 & 22.42 & 0.949 & 1.537 & 0.461 \\
\hline LSB700 & 0.995 & 0.0089 & 28.74 & 0.923 & 2.098 & 0.460 \\
\hline
\end{tabular}


loess, and the larger the initial concentration of $\mathrm{Cd}$ (II), the greater the increase of adsorption capacity. The Langmuir model can well describe the adsorption isothermal behaviours of $\mathrm{Cd}(\mathrm{II})$ by biochar-amended loesses.

\section{Acknowledgements}

This work was supported by the Project for Science and Technology Research, Ministry of Education of Gansu Province, under grant No. 2014B-038; the Nature Science Foundation Project in Gansu province under grant No. 1506RJZA077; the Project for Lanzhou Science and Technology Bureau under grant No. 2014-1-189; and the Youth Science Fund Project of Lanzhou Jiaotong University under grant No. 2013014.

\section{References}

1. DEVECI H., KAR Y. Adsorption of hexavalent chromium from aqueous solutions by bio-chars obtained during biomass pyrolysis. J. Ind. Eng. Chem. 19, 190, 2013.

2. TAN X.P., LIU Y.J., YAN K.H., WANG Z.Q., LU G.N., HE Y.K., HE W.X. Differences in the response of soil dehydrogenase activity to $\mathrm{Cd}$ contamination are determined by the different substrates used for its determination. Chemosphere. 169, 324, 2017.

3. UCHIMIYA M., LIMA I. M., THOMAS K.K., CHANG S., WARTELLE L.H., RODGERS J.E. Immobilization of heavy metal ions(Cu II, Cd II, Ni II, and Pb II) by broiler litter-lerivedbiochars in water and soil. J.Agr. Food Chem. $\mathbf{5 8}(9), 5538,2010$.

4. SHENG Y., ZHAN Y., ZHU L. Reduced carbon sequestration potential of biochar in acidic soil. Sci. Total Environ. 572, 129, 2016.

5. SUN K., KEILUWEIT M., KLEBER M., PAN Z., XING B. Sorption of fluorinated herbicides to plant biomass-derived biochars as a function of molecular structure. Bioresour. Technol. 102 (21), 9897, 2011.

6. Inyang M., Gao B., Yao Y., XUE Y., ZIMMERMAN A.R., PULLAMMANAPPALLIL P., CAO X. Removal of heavy metals fromaqueous solution by biochars derived from anaerobically digested biomass. Bioresour.Technol. 110, 50, 2012.

7. WANG B., LI C., LIANG H. Bioleaching of heavy metal from woody biochar using Acidithiobacillusferrooxidans and activation for adsorption. Bioresour.Technol. 146, 803, 2013.

8. BARROW C.J. Biochar: Potential for countering land degradation and for improving agriculture. Applied Geography. 34, 21, 2012.

9. KHODADAD C.L.M., ZIMMERMAN A.R., GREEN S.J., UTHANDI S., FOSTER J.S. Taxa-specific changes in soil microbial community composition induced by pyrogenic carbon amendments. Soil Biol. Biochem. 43 (2), 385, 2011.

10. BEESLEY L., MARMIROLI M. The immobilisation and retention of soluble arsenic, cadmium and zinc by biochar. Environ. Pollut. 159 (2), 474, 2011.

11. ZHENG H., WANG Z.Y., ZHAO J., HERBERT S., XING B. Sorption of antibiotic sulfamethoxazole varies with biochars produced at different temperatures. Environ. Pollut. 181, 60, 2013.
12. SUN K., JIN J., KEILUWEIT M., KLEBER M., WANG Z., PAN Z., XING B. Polar and aliphatic domains regulate sorption of phthalic acid esters (PAEs) to biochars. Bioresour. Technol. 118, 120, 2012.

13. DAI X.H. Current situation and thought about treatment and disposal of Urban sludge in china. Water and Wastewater Engineering. 38 (2), 1, 2012 [In Chinese].

14. AGRAFIOTI E., BOURAS G., KALDERIS D., DIAMADOPOULOS E. Biochar production by sewage sludge pyrolysis. J. Anal. Appl. Pyrol. 101 (5), 72, 2013

15. LIU T., LIU B., ZHANG W. Nutrients and heavy metals in biochar produced by sewage sludge pyrolysis: its application in soil amendment. Pol. J. Environ. Stud. 23 (1), 271, 2014.

16. CHEN T., ZHOU Z.Y., HAN R., MENG R.H., WANG H.T., LU W.J. Adsorption of cadmium by biochar derived from municipal sewage sludge: Impact factors and adsorption mechanism. Chemosphere. 134, 286, 2015.

17. ANGIN D. Effect of pyrolysis temperature and heating rate on biochar obtained from pyrolysis of safflower seed press cake. Bioresour.Technol. 128 (1), 593, 2013.

18. KUMAR A., JENA H.M. High surface area microporous activated carbons prepared from Fox nut ( Euryale ferox ) shell by zinc chloride activation. Appl. Surf. Sci. 356, 753, 2015.

19. CHEN B.Y., CHENG L.L. A Modified HF-Kjeldahl Method for Determining Total Nitrogen in Soil. Pedosphere. 7 (4), 375, 1997.

20. CHEN B.L., JOHNSON L.J., CHEFETZ B., ZHU L., XING B. Sorption of polar and nonpolar aromatic organic contaminants by plant cuticular materials:role of polarity and accessibility. Environ. Sci. Technol. 39 (16), 6138, 2005.

21. YOSHIDA T., ANTAL M.J. Sewage Sludge Carbonization for Terra Preta Applications. Energ. Fuel. 23 (11), 5454, 2009.

22. JIANG J., XU R.K., JIANG T.Y., LI Z. Immobilization of $\mathrm{Cu}(\mathrm{II}), \mathrm{Pb}(\mathrm{II})$ and $\mathrm{Cd}(\mathrm{II})$ by the addition of rice straw derived biochar to a simulated polluted Ultisol. J. Hazard. Mater. 229-230, 145, 2012.

23. QIN Q., WANG Q., FU D., MA J. An efficient approach for $\mathrm{Pb}(\mathrm{II})$ and $\mathrm{Cd}(\mathrm{II})$ removal using manganese dioxide formed in situ. Chem. Eng. J. 172, 68, 2011.

24. VITELA-RODRIGUEZ A.V., RANGEL-MENDEZ J.R. Arsenic removal by modified activated carbons with iron hydro(oxide) nanoparticles. J. Environ. Manage. 114, 225, 2013.

25. KOŁODYŃSKA D., Wnętrzak R., Leahy J.J., Hayes M.H.B., Kwapiński W., Hubicki Z. Kinetic and adsorptive characterization of biochar in metal ions removal. Chem. Eng. J. 197, 295, 2012.

26. WANG L., Zhao B.W., Ma F.F., XU R.Z., LI Y.W. Effect of biochar derived from potato straw on adsorption of $\mathrm{Cd}(\mathrm{II})$ onto loess. Environmental Chemistry. 35 (7), 1422, 2016 [In Chinese].

27. CHEN T., ZHANG Y.X., WANG H.T., WU W.J., ZHOU Z.Z., ZHANG Y.C., REN L.L. Influence of pyrolysis temperature on characteristics and heavy metal adsorptive performance of biochar derived from municipal sewage sludge. Bioresour.Technol. 164 (7), 47, 2014.

28. ZHENG H., WANG Z., DENG X., ZHAO J., LUO Y., NOVAK J., XING B. Characteristics and nutrient values of biochars produced from giant reed at different temperatures. Bioresour.Technol. 130, 463, 2013.

29. VARADARAJAN R., GOVINDAN V., SWAMINATHAN G. Removal of copper using clay admixed with quarry fines as landfill liners. Pol. J. Environ. Stud. 25, 1, 2016. 